G. W. Bailey, J. M. Corbett, R. V. W. Dimlich, J. R. Michael, N. J. Zaluzec. Eds

Proceedings of Microscopy and Microanalysis, 1996

Copyright $@ 1996$ by MSA. Published by San Francisco Press, Inc., Box 426800. San Francisco, CA 94142-680K, USA

\title{
TEM STUDY OF PRECIPITATION IN A NiAl-3Ti-0.5Hf SINGLE-CRYSTAL ALLOY
}

\author{
A. Garg, R. D. Noebe, J. M. Howe*, A. W. Wilson* and V. Levit**
}

NASA Lewis Research Center, Cleveland, $\mathrm{OH} 44135$

* Dept. of Materials Science and Engineering, University of Virginia, Charlottesville, VA 22903

** Dept. of Materials Science and Engineering, University of Florida, Gainesville, FL 32611

Three directionally solidified NiAl single-crystal alloys, NiAl-3Ti, NiAl-0.5Hf and NiAl-3Ti-0.5Hf (at.\%), were grown by a Bridgeman technique using high purity alumina crucibles. The ingots were homogenized for $32 \mathrm{~h}$ at $1644 \mathrm{~K}$ followed by aging for $6 \mathrm{~h}$ at $1255 \mathrm{~K}$ and finally furnace cooled under an argon atmosphere. This heat treatment was found to be very effective in dissolving Hf-rich interdendritic particles that were present in the as-cast structure, and at the same time it produced fine second-phase precipitates in the alloy.

Samples for transmission electron microscopy (TEM) were prepared from $3 \mathrm{~mm}$ diameter cylinders electro-discharge machined from the heat-treated ingots. Slices sectioned from the cylinders were mechanically ground and electrochemically thinned in a twin-jet Tenupol-3 polisher. Microstructural and energy-dispersive $X$-ray spectroscopy (EDXS) studies were conducted in a Philips 400T TEM equipped with a double tilt goniometer and a KEVEX $\mathrm{Si} / \mathrm{Li} \mathrm{X}$-ray detector.

TEM microstructures of the NiAl-3Ti and NiAl-0.5Hf samples were featureless except for the presence of some random dislocations. No homogeneous precipitation was observed in either of the two alloys suggesting that 3 at.\% $\mathrm{Ti}$ in the first alloy and 0.5 at.\% $\mathrm{Hf}$ in the second alloy were in solid solution in the NiAl matrix. The microstructure of the NiAl-3Ti-0.5Hf alloy was, however, very different and showed a high density of precipitates. A TEM bright-field image of the alloy close to a $\left\langle 001>_{\mathrm{NiAl}}\right.$ zone-axis is presented in Fig. 1(a). It shows a high density of fine precipitates $($ size $\sim 5-50 \mathrm{~nm}$ ) distributed uniformly throughout the foil, and some coarse precipitates (size $\sim 100$ $700 \mathrm{~nm})$ nucleated preferentially on dislocations on $\{100\}_{\text {NiAl }}$ planes. The coarse precipitates were always associated with precipitate free zones. The fine precipitates, shown at a higher magnification in Fig. 1(b), clearly exhibited a plate-shape morphology with associated coherency strain. Using EDXS, electron diffraction (Fig. 1(c)) and trace analysis these fine precipitates were identified as $\mathrm{Ni}_{2} \mathrm{AlTi}$ Heusler phase $(\mathrm{L2}, \mathrm{a}=0.587 \mathrm{~nm})$ formed on the $\{100\}_{\mathrm{NiAl}}$ planes with a cube-on-cube orientation relationship. Two types of coarse precipitates were found to nucleate on dislocations; edge-on plates (marked T, size $\sim 100-250 \mathrm{~nm}$ ) and almost equiaxed precipitates (marked $\mathrm{H}$, size $\sim$ $200-700 \mathrm{~nm}$ ). These precipitates were also found to be Heusler phases; $\mathrm{T}: \mathrm{Ni}_{2} \mathrm{AlTi}, \mathrm{H}: \mathrm{Ni}_{2} \mathrm{AlHf}$ $\left(\mathrm{L} 2_{1}, \mathrm{a}=0.608 \mathrm{~nm}\right)$. Both of these phases are formed by further ordering of the B2 structure of $\mathrm{NiAl}$ (ordered BCC, $\mathrm{a}=0.289 \mathrm{~nm}$ ) during cooling 1,2 . The lattice misfits of the $\mathrm{Ni}_{2} \mathrm{AlTi}$ and $\mathrm{Ni}_{2} \mathrm{AlHf}$ phases with the NiAl matrix are $1.5 \%$ and $5.2 \%$, respectively. Due to large misfit of the $\mathrm{Ni}_{2} \mathrm{AlHf}$ phase, a square network of misfit dislocations of spacing $\sim 5.6 \mathrm{~nm}$ was often observed at the $\mathrm{Ni}_{2} \mathrm{AlHf} / \mathrm{NiAl}$ interface, which made its presence unmistakable and unique.

Dislocation segments lying along the $\left\langle 110>_{\mathrm{NiAl}}\right.$ directions were often unstable and found to sharply bend along the $\langle 100\rangle_{\mathrm{NiAl}}$ directions, giving them a zigzag appearance (arrows in Fig 1(a)). Preferred nucleation of the $\mathrm{Ni}_{2} \mathrm{AlTi}$ precipitates on such segments produced a saw-tooth appearance. In several regions of the foil, a dense precipitation of large $\mathrm{Ni}_{2} \mathrm{AlTi}$ plates and some $\mathrm{Ni}_{2} \mathrm{AlHf}$ 
precipitates were observed along the $\langle 110\rangle$ directions in a $<001\rangle_{\mathrm{NiAl}}$ zone-axis (Fig 2). This is believed to be due to preferential nucleation of the $\mathrm{Ni}_{2} \mathrm{AlTi}$ precipitates possibly on prismatic dislocation loops.

A high density of fine precipitation as seen in Fig. 1(a) is expected to enhance the creep properties of $\mathrm{NiAl}$ single crystals significantly and is under investigation.

References

1. R. D. Field et al., Scripta Metallurgica, 23(1989)1469.

2. N. C. Tso and J. M. Sanchez, MRS Symp. Proc., Vol. 133(1989)63.

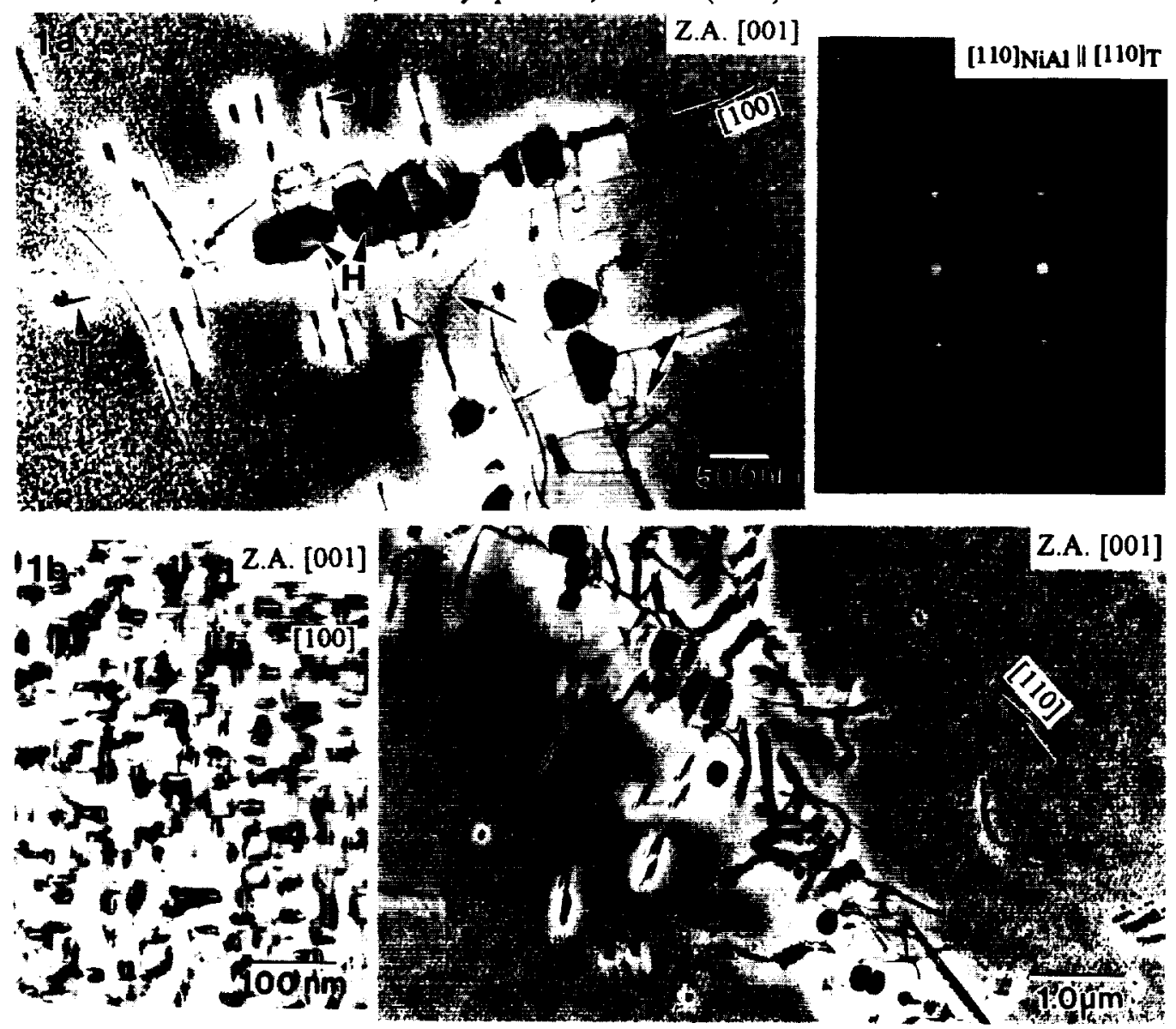

Fig. 1 (a) General microstructure of the NiAl-3Ti-0.5Hf single-crystal alloy in the as-heat treated condition. A higher magnification view of region $F$ and its $S A D P$ are shown in $(b, c)$, respectively. Fig. 2 Preferential precipitation of large $\mathrm{Ni}_{2} \mathrm{AlTi}$ plates and equiaxed $\mathrm{Ni}_{2} \mathrm{AlHf}$ phase along a $<110>$ direction in a $\langle 001\rangle_{\mathrm{NiAl}}$ zone-axis. 